University of Louisville

ThinkIR: The University of Louisville's Institutional Repository

\title{
The problem of luck and free will : how counterfactuals can help.
}

\author{
Zach Smith \\ University of Louisville
}

Follow this and additional works at: https://ir.library.louisville.edu/honors

Part of the Metaphysics Commons, Other Philosophy Commons, and the Philosophy of Language Commons

\section{Recommended Citation}

Smith, Zach, "The problem of luck and free will : how counterfactuals can help." (2017). College of Arts \& Sciences Senior Honors Theses. Paper 140.

http://doi.org/10.18297/honors/140

This Senior Honors Thesis is brought to you for free and open access by the College of Arts \& Sciences at ThinkIR: The University of Louisville's Institutional Repository. It has been accepted for inclusion in College of Arts \& Sciences Senior Honors Theses by an authorized administrator of ThinkIR: The University of Louisville's Institutional Repository. This title appears here courtesy of the author, who has retained all other copyrights. For more information, please contact thinkir@louisville.edu. 
By

Zach Smith

College of Arts and Sciences of the University of Louisville

Submitted in partial fulfillment of the requirements for Graduation summa cum laude and for Graduation with Honors from the Department of Philosophy

\author{
Department of Philosophy \\ University of Louisville \\ Louisville, Kentucky
}

May 2017 


\begin{abstract}
THE PROBLEM OF LUCK AND FREE WILL: HOW COUNTERFACTUALS CAN HELP

Zach Smith

March 2017

For free will theorists, the problem of luck has been a constant source of consternation. Peter van Inwagen presents a version immune to even agent-causal conceptions of free will. However, van Inwagen's version of the problem can be avoided if there are true propositions taking the form of counterfactuals of creaturely freedom. There are good reasons to think that there are, and no comparably good reasons to think that there are not. This defense is also resistant to common attacks based on foreknowledge and the grounding of the truth of these counterfactuals.
\end{abstract}

Keywords: free will, indeterminism, luck objection, counterfactuals of freedom 


\section{LAY SUMMARY}

We all, most would concede, at least have the illusion of being free creatures. We experience and apprehend a sense of freedom in our actions. We feel as though our actions are not determined by anything other than our own wills. However, this idea is at some odds with our understanding of the universe. We have seemingly good reasons to think that the universe operates either deterministically or probabilistically. Determinism is the idea that the laws of nature determine an exact future. There would be no free will as we understand it because we do not determine our actions; rather, the laws of nature determine our actions. However, we may also have reason to think the universe operates indeterministically, or probabilistically. That is to say, there may be some kind of chance variation in the events of the universe like the kind found in some interpretations of quantum mechanics. There would be no free will on this view either as decisions are not the product of our wills but rather chance, like a cosmic roll of the dice. Both of these, it seems, are incompatible with free will. If this is true, then it seems free will cannot possibly exist. However, we also have seemingly good reasons to think free will does exist. Our experience with moral responsibility and personal decision making leads us to believe free will is necessary for understanding our lives. This is the problem of free will.

In this paper, I will focus on resolving the incompatibility of free will and indeterminism. A prominent philosopher in the field of free will, Peter van Inwagen, provides an argument that seems to show that free will always breaks down into probability. I think that by examining the thought experiment, we can come up with good reasons to think that this will not happen. If there are certain truths about a person's free decisions (namely their consistency), we will avoid van Inwagen's objection, and have a reason to think free will is not impossible. 


\section{TABLE OF CONTENTS}

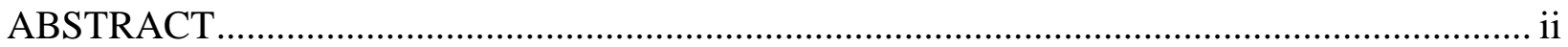

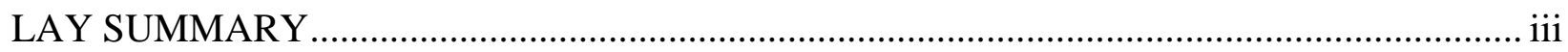

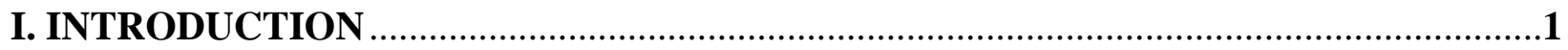

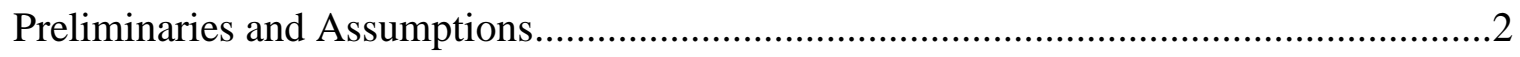

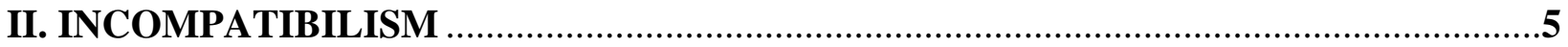

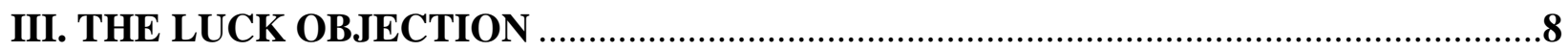

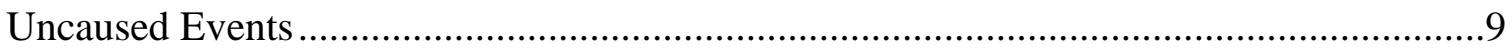

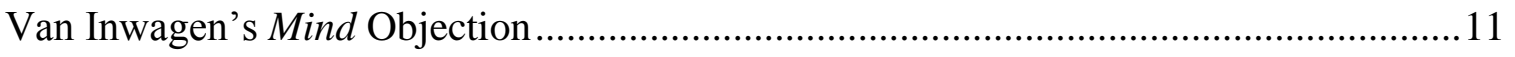

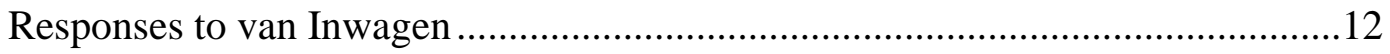

IV. A NEW RESPONSE TO THE MIND OBJECTION ...............................................13

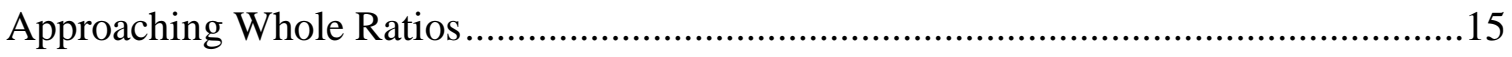

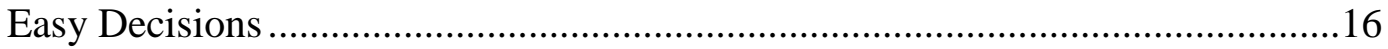

Difficult Decisions ............................................................................... 18

Subjunctive Counterfactuals ...................................................................19

Significant Distinctions in Counterfactual Semantics ..........................24

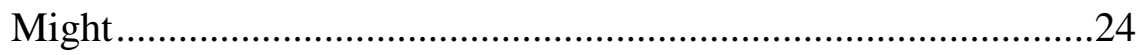

Could/Can and Would/Will ....................................................26

The Counterfactual Solution ..............................................................................2

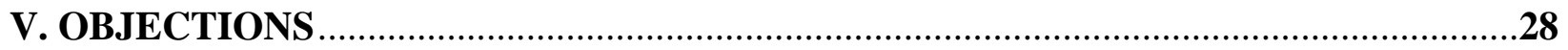

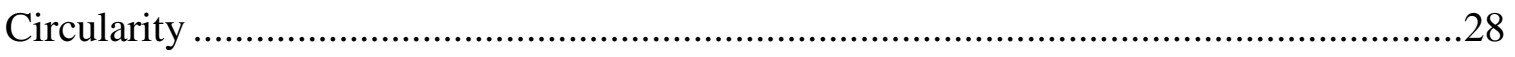

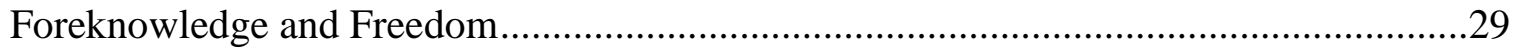

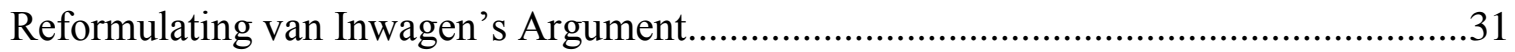


The Grounding Objection .

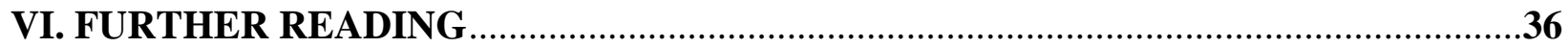

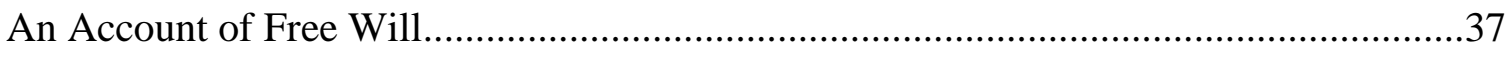

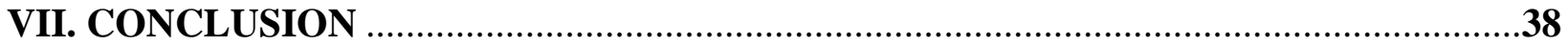

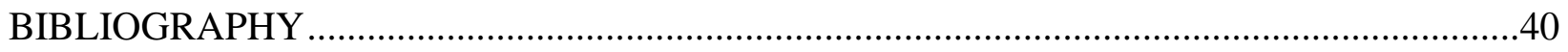




\section{THE PROBLEM OF LUCK AND FREE WILL: HOW COUNTERFACTUALS CAN HELP}

\section{Introduction}

The problem of free will has experienced somewhat of a resurgence in recent years, due partly to the move away from logical positivism and its cold, deterministic view of the universe. Metaphysics once more came alive, and the free will problem was seen to have meaning apart from what sheer empiricism could provide. Philosophers began to sincerely consider the lived experience of human beings, and in so doing widely recognized the apprehension of a sense of freedom in action. Doing so further legitimized the need for another pass at the problem of free will, and modern philosophers from all disciplines surveyed the problem and its relation to metaphysics, ethics, phenomenology, and the like. Yet, the determinism from the modernist era remained fresh in academia, and the death of logical positivism forced determinist-minded philosophers to take this problem seriously. People, it seemed, at least had the illusion of being free creatures. Therefore, in an attempt to resolve this disparity, philosophers tried to come up with a theory that both allowed them to affirm both the truth of a determinate universe and the truth of creaturely free will. This thesis was called compatibilism, and was nearly a universally accepted theory for the greater part of the $20^{\text {th }}$ century. However, with philosophers like Peter van Inwagen came the advent of incompatibilism, a position denying that creaturely free will could ever exist inside a determined universe. Van Inwagen's incompatibilist argument changed the landscape of philosophical discourse on free will, determinism, and compatibilism. Van Inwagen himself being convinced of the truth of creaturely free will nevertheless struggles with one of the strongest objections to current theories of free will. This essay concerns itself with this very objection, sometimes called the luck objection or the Mind objection due to its frequent appearance in the esteemed philosophical journal. I will be taking a great deal of advice from van 
Inwagen's "How to Think About the Problem of Free Will” insofar as his recommendation to very clearly define the terms and assumptions so as to be incredibly explicit about just what I am and what I am not talking about.

Beginning with an argument for incompatibilism, I will show that the incompatibility of free will and determinism is plausibly true, and with this comes an entirely new issue also involving compatibility. This is the primary thrust of the luck objection: in some sense, free will may possibly be incompatible with determinism, but it is also incompatible with indeterminism. The intuition behind the luck objection is that indeterminism is in some way freedom prohibiting. This could be due to the very nature of so-called "uncaused events," but typically the incompatibility arises from the aura of chance surrounding indeterministic decisions. For if decisions are a mere matter of chance, then they do not seem to be free in the sense that free will theorists wish to affirm.

The central claim I hope to prove is that arguments for the incompatibility of free will and indeterminism (like the Mind argument) are fallacious. In particular, van Inwagen's version of the argument can be avoided by appeal to the truth of certain subjunctive conditionals, called counterfactuals of freedom, about an agent featured in the argument. If these counterfactuals are indeed true, then the mechanics of the argument resulting in the conclusion will break down, leaving us with no intuition that free decisions are a mere matter of chance. This solution will hold up under scrutiny, as criticisms of it are based on faulty intuitions or dubious and ambiguous conditions for the grounding of the truth of such counterfactuals.

\section{Preliminaries and Assumptions}

Peter van Inwagen provides a very clear, helpful framework for discussing the "problem of free will" in his essay "How to Think about the Problem of Free Will", which I will be using 
to expedite the preliminary considerations of the thesis. Van Inwagen thinks that a great deal of confusion has been raised by inconsistent usage of terms throughout the philosophical literature on freedom of the will, determinism, and compatibilism. In order to combat this, I will be following his recommendations to "define every term you use that is neither a word or phrase of ordinary language nor a technical term of some discipline other than philosophy" beginning with a clear definition of the problem of free will. ${ }^{1}$ After all, there are many problems regarding free will, and it is not altogether clear what exactly the aforementioned problem refers to. It may seem intuitively obvious to the reader, but that would indeed be an assumption on his or her part, which is the beginning of the confusion, per van Inwagen. Therefore, I will define the problem of free will as the following:

There are a great deal of strong arguments against the compatibility of free will and determinism. There are likewise a great deal of strong arguments against the compatibility of free will and indeterminism. Therefore, the concept of free will seems incoherent, and the thing free will cannot exist. However, there are a great deal of strong arguments for the indispensability of free will in moral responsibility. Since the existence of moral responsibility is evident, free will must necessarily exist. The "problem of free will" is in finding out which of these arguments are false. ${ }^{2}$

This is a condensed version of van Inwagen's definition of the problem, and for clarity's sake, I will also adopt his definitions of the relevant terms used in expounding the problem of free will, beginning with the free-will thesis itself:

\footnotetext{
${ }^{1}$ Peter Van Inwagen, "How to Think about the Problem of Free Will," The Journal of Ethics 12, no. 3-4
} (2006): 328.

2 Ibid., 327-328. 
- The free-will thesis is the thesis that we are sometimes in the following position with respect to a contemplated future act: we simultaneously have both the following abilities: the ability to perform that act and the ability to refrain from performing that act (This entails that we have been in the following position: for something we did do, we were at some point prior to our doing it able to refrain from doing it, able not to do it). ${ }^{3}$

- Determinism is the thesis that the past and the laws of nature together determine, at every moment, a unique future (The denial of determinism is indeterminism). ${ }^{4}$

- Compatibilism is the thesis that determinism and the free-will thesis could both be true (And incompatibilism is the denial of compatibilism). ${ }^{5}$

- Libertarianism is the conjunction of the free-will thesis and incompatibilism (Libertarianism thus entails indeterminism). ${ }^{6}$

- Hard determinism is the conjunction of determinism and incompatibilism (Hard determinism thus entails the denial of the free-will thesis). ${ }^{7}$

A few words before the beginning of the thesis would be helpful as commentary on some of these definitions. I take indeterminism at its most general of meanings: indeterminism is just the denial of the determinism thesis. Indeterminism therefore does not mean this: anytime that the laws of nature in conjunction with the past do not together determine the future, the future is a matter of chance. This, however, seems to be the common understanding of "indeterminism" by

\footnotetext{
${ }^{3}$ Ibid., 329. Van Inwagen also includes a warning not to define free will as simply "whatever sort of freedom is required for moral responsibility or compatibilist free will."

${ }^{4}$ Ibid., 330.

${ }^{5}$ Ibid.

${ }^{6}$ Ibid.

${ }^{7}$ Ibid.
} 
the proponents of the Mind objection. If indeterminism is taken to simply mean "a matter of chance", given we take chance at its common language definition, I believe it patently obvious that free will can have nothing to do with it. It ends the discussion before it can begin. Since indeterminism is the issue we must contend with in talking about luck and free will, it should go without saying that incompatibilism will be the assumed framework under which I shall discuss objections like those found in Mind. Any references to compatibilism will be brief, as it is not the focus of this paper. To quote the sentiment of the Gospel of John, were every idea on compatibilism to be recorded, I suppose that the world itself could not contain all the books that would be written.

\section{Incompatibilism}

For decades, the prevailing view on the problem of free will has been and is now that free will exists and is compatible with determinism. Adherents of this view have argued that determinism need not disappoint us with the loss of freedom, as the two can coexist quite nicely. There have been various ways of arguing for such a conclusion. Harry Frankfurt's thought experiments have been some of the most enlightening and convincing examples of support for the compatibilist position. ${ }^{8}$ Many compatibilists, like P.F. Strawson, have made the compatibility of moral responsibility their primary concern. ${ }^{9}$ In recent years, minds like John Martin Fischer have approached the problem from incredibly unique perspectives that modernize compatibilism in order to deal with the current state of the problem of free will. Fischer has argued for semicompatibilism, or a compatibilist account of determinism that deals primarily with making moral responsibility compatible with determinism instead of free will, acknowledging that free $828-39$.

${ }^{8}$ Harry G. Frankfurt, “Alternate Possibilities and Moral Responsibility,” Journal of Philosophy 66 (1969):

${ }^{9}$ P.F. Strawson, Freedom and Resentment, and Other Essays. (Abingdon: Routledge, 1963) 
will may very well be incompatible with determinism. ${ }^{10}$ But what prompted this modernization of compatibilism? I believe this is a reaction to the strong case for incompatibilism made at the hands of philosophers like Peter van Inwagen ${ }^{11}$ and Roderick Chisholm; ${ }^{12}$ incompatibilism became a serious consideration for those who thought carefully about the problem of free will. Informally, the argument for incompatibilism is that, on determinism, the laws of nature and state of the universe at any moment together determine a unique future. No one has any say about the laws of nature or the state of the universe, so no one has any control over the future. Thus, free will does not exist. Peter van Inwagen provides the following logical construction of the incompatibilist argument: ${ }^{13}$ Let ' $\square$ ' represent necessity, ' $\mathrm{p} p$ ' represent ' $\mathrm{p}$ and no one has or ever had any choice about whether p', 'L' represent the conjunction of the laws of nature as a single proposition, ' $\mathrm{P}_{0}$ ' represent some proposition that describes the state of the world at some time in the remote past, and 'P' represent some true proposition.

Given the inference rules

$$
\begin{aligned}
& \alpha \square p \vdash \mathrm{N} p \\
& \beta \mathrm{N} p, \mathrm{~N}(p \supset q) \vdash \mathrm{N} q .
\end{aligned}
$$

We can argue

$$
\begin{aligned}
& \text { (1) } \square\left(\left(\mathrm{P}_{0} \& \mathrm{~L}\right) \supset \mathrm{P}\right) \text { from Determinism }{ }^{14} \\
& \text { (2) } \square\left(\left(\mathrm{P}_{0} \supset(\mathrm{L} \supset \mathrm{P})\right)\right. \text { from 1, standard logic }
\end{aligned}
$$

${ }^{10}$ John M. Fischer, "Compatibilism," in Four Views on Free Will, by John Martin Fischer, Robert Kane, Derk Pereboom, and Manuel Vargas (Oxford: Blackwell, 2007) 44-84.

${ }^{11}$ Peter van Inwagen, An Essay on Free Will (Oxford: Clarendon Press, 1983).

${ }^{12}$ Roderick M. Chisholm, "Freedom and Action," in Freedom and Responsibility, ed. Keith Lehrer (New York: Random House, 1966), 11-44.

${ }^{13}$ Peter van Inwagen, "Free Will Remains a Mystery," Philosophical Perspectives 14 (2000): 2.

${ }^{14}$ See definition of "determinism", p. 3. 
(3) $\mathrm{N}\left(\left(\mathrm{P}_{0} \supset(\mathrm{L} \supset \mathrm{P})\right)\right.$ from $2, \alpha$

(4) $\mathrm{NP}_{0}$ as a premise

(5) $\mathrm{N}(\mathrm{L} \supset \mathrm{P})$ from $3,4, \beta$

(6) NL as a premise

(7) NP from 5, 6, $\beta$.

In a more readable language, this translates to

$\alpha$ It is deducible that no one has or ever had any choice about a certain proposition if that proposition is true in all possible worlds.

$\beta$ Given that no one has or ever had any choice about a proposition $p$ and $p$ 's entailment of $q$, it is deducible that no one has or ever had any choice about a proposition $q$.

(1) Necessarily, the past and the laws of nature together determine, at every moment, a unique future.

(2) Necessarily, a certain past implies that if there are certain laws of nature, then a unique future will result. This is by logical exportation.

(3) Because this is necessary, no one has or ever had any choice about whether (2) is true.

(4) No one has or ever had any choice about whether the past is a certain way.

(5) No one has or ever had any choice about whether the laws of nature imply a unique future.

(6) No one has or ever had any choice about whether the laws of nature are a certain way.

(7) Therefore, no one has or ever had any choice about the future.

There have been challenges to $\beta$ given by Thomas McKay and David Johnson, ${ }^{15}$ but van Inwagen deals with them extensively; he modifies $\beta$ to maintain the soundness of his argument

15 Thomas McKay and David Johnson, "A Reconsideration of an Argument against Compatibilism," Philosophical Topics 24 (1996): 113-122. 
by proceeding with a modified definition of $\mathrm{N} p \cdot{ }^{16}$ I have used the original formulation to aid readability, but the modified version of $\mathrm{N} p$ is " $p$ and every region to which anyone has, or ever had, exact access is a sub-region of p" where regions refer to the logical space of the propositions. ${ }^{17}$ This, according to van Inwagen, now captures the idea of sheer incompatibility between determinism and free will that the previous argument did not.

This is commonly referred to as the Consequence Argument, and its various forms have been around since its conception in the late $20^{\text {th }}$ century. So the case for incompatibilism seems strong. Without a definitive rebuttal of $\alpha$ or $\beta$, the conclusion follows. The argument is valid, and the room with which to question its soundness is small indeed. If the free-will thesis is therefore incompatible with determinism, the question arises: is the free-will thesis compatible with indeterminism?

\section{The Luck Objection}

What does it mean for our choices to be indeterminate? This is the question that pervades the literature on objections to incompatibilism. A great deal of objections to libertarianism are based on the incompatibility of indeterminism and free will. In this sense, it is a sort of reversal of the typical incompatibilist arguments. Derk Pereboom, a hard determinist, describes the problem thusly: "If decisions were indeterministic events of the sort specified by [event-causal libertarianism], then agents would have no more control over their actions than they would if determinism were true, and such control is insufficient for responsibility." ${ }^{18}$ Van Inwagen refers

\footnotetext{
${ }^{16}$ Peter van Inwagen, "Free Will Remains a Mystery," Philosophical Perspectives 14 (2000): 3-10.

${ }^{17}$ Ibid., 8.

${ }^{18}$ Derk Pereboom, Living without Free Will (Cambridge: Cambridge University Press, 2001), 46.
} 
to it as the Mind objection because it so often appears in the eponymous philosophical journal. ${ }^{19}$ The typical formulation of the argument usually begins with an assumption that, if the actions of an agent are undetermined, then there is no prior event that necessitates its occurring; those actions are therefore a matter of chance. If the actions are a matter of chance, then the agent can hardly be said to have free will. Our sense of choosing between two alternatives, deciding to do $A$ or refrain from $A$, is only a free act if the decision is up to us. If the decision is a matter of chance, then it in no way seems as if it was up to us; therefore, free will seems incompatible with indeterminism. Does this objection from luck have force?

\section{Uncaused Events}

I see no necessary connection between indeterminism and chance, especially on the formulation of determinism used previously in the Consequence Argument. I think it is therefore important to examine what motivations there might be for such a connection. It seems to me that the primary motivation for this objection comes from the perception of libertarian free will decisions as "uncaused events". The term "uncaused" here is loaded with all kinds of presumptions and ambiguities we must unpack in order to make sense of the phrase "uncaused events". What libertarians typically mean by "uncaused events" is that the events are not caused deterministically in a physicalist sense. That is, they may have preceding causes, but these cannot be both sufficient and physical. There are many different ways libertarians have thought about causes of freely willed acts. One such way would be Kane's concept of "self-forming actions", where decisions can be caused by the character that the agents have built for themselves over their lifetime. ${ }^{20}$ Another way of conceiving of causes of freely willed events would be

\footnotetext{
${ }^{19}$ Peter van Inwagen, “Free Will Remains a Mystery,” Philosophical Perspectives 14 (2000): 10.

${ }^{20}$ Robert Kane, "Libertarianism," in Four Views on Free Will, by John Martin Fischer, Robert Kane, Derk Pereboom, and Manuel Vargas (Oxford: Blackwell, 2007)
} 
through the agent making rational deliberations between several options. These kinds of causes can be seen in some sense as explanatorily prior to the actions, but not deterministic in the sense that they are the ultimate result of the fixed past and the laws of nature. Given this nuanced stance on "uncaused events", it is hopefully clear that libertarians do not mean that there are literally no causes whatsoever of any freely willed actions. I cannot think of a single example of truly uncaused events, where any semblance of a cause of any sort is entirely absent. Even in fields like quantum mechanics, when particles fluctuate into existence from the quantum vacuum "uncaused" (in the sense of having no Aristotelean efficient cause), there's still the quantum vacuum itself to provide the material cause for the particles' existence! If there are such things as truly uncaused events, I can make no sense of them in a coherent fashion. Objections based on the basis of the inscrutability of "uncaused events" therefore must deal with the libertarians' conceptions of causes before chance can be considered a necessary consequence of indeterminism.

There is no logical connection with indeterminism and chance, and so I fail to see why in all possible worlds where determinism is not true, chance is the only decisive factor in decision making. In simply denying that the conjunction laws of nature and the past together determine a unique future, there is no logical commitment to luck taking precedence over all actions. It seems to me there are a multitude of ways to conceive of decision making that do not rely on chance, the most popular of which is through agent causation. Agent causation claims that there are events in the world caused wholly or in part by agents themselves, and there is nothing that determined the agents to act this way other than their own wills. Van Inwagen calls it "a relation that agents - thinking or rational substances - bear to events." 21 This relation is supposed to

\footnotetext{
${ }^{21}$ Peter van Inwagen, “Free Will Remains a Mystery,” Philosophical Perspectives 14 (2000): 12.
} 
defeat the luck objection and apparent incompatibility of free will and indeterminism by providing a way for events to occur, in an indeterminate sense, without the necessity of chance. However, van Inwagen thinks that agent causation will be of no use in dealing with the luck objection. This is on the basis of the appearance of chance in situations even when agent causation is taken into account. I will attempt to show how his version of the argument can be averted by challenging its mechanics with the introduction of certain counterfactuals.

\section{Van Inwagen's Mind Objection}

Van Inwagen presents the following version of the Mind objection and modifies it to deal with agent causation. ${ }^{22}$ He supposes that undetermined acts occur, and that an agent, Alice, is about to partake in one. Alice is in a very difficult position where she must choose to tell the truth or to lie. She very seriously considers both and, after hard deliberation, she decides to tell the truth. Then, van Inwagen supposes that God reverts the universe to the minute before Alice tells the truth. Since the act is undetermined, we can have no idea as to whether or not Alice will tell the truth. Van Inwagen then asks us to imagine that God reverts the universe one thousand times and asks us what we ought to expect to observe. He says, "Well, again, we can't say what would have happened, but we can say what would probably have happened: sometimes Alice would have lied and sometimes she would have told the truth. As the number of 'replays' increases, we observers shall almost certainly observe the ratio of the outcome 'truth' to the

outcome 'lie' settling down to, converging on, some value." ${ }^{23}$ Supposing this value comes out to around .5, what reason have we to resist the conclusion that Alice's decision is but a matter of chance? Van Inwagen thinks we have none, and this is the plausible version of the Mind

\footnotetext{
${ }^{22}$ Ibid., 14-18.

${ }^{23}$ Ibid., 14.
} 
argument that makes free will plausibly incompatible with indeterminism. Van Inwagen goes a step further in modifying this objection to steel it from attempts to undermine it using agent causation. He supposes that Alice agent-causes the cerebral events that result in either telling the truth or lying. But van Inwagen thinks that "its coming to pass that Alice agent-causes truthantecedent cerebral events" is itself subject to the question of chance. ${ }^{24}$ Certainly, we might say, Alice is the agent cause of truth telling, but why oughtn't we think that event, the coming to pass that Alice agent-causes an event, is a matter of chance? There appears to be an infinite regress of events: the agent-causing, and the coming to pass of the agent causing, the agent-causing of its coming to pass of the original agent-causing repeated ad infinitum as they build on to each other. If the ratio of events of agent-caused decisions in this regress also converges to around .5 , then we have no reason, per van Inwagen, to think it not a matter of chance.

Responses to van Inwagen

There are several objections to van Inwagen's conception of the Mind argument, mostly arising from van Inwagen's characterization of chance in free will. Meghan Griffith provides several reasons for thinking van Inwagen's Mind objection can be surmounted. First, she points out that, for all events in the infinite regress, they can all be agent-caused. ${ }^{25}$ However, more interestingly, she also claims that van Inwagen's distinction between the event-action and the agent-causing of that event as two separate events is superfluous. "It is open to the agent-causal theorist that what Alice directly causes is her action. And the exertion of her causal power just is her action. There is no multiplication of events. There is no separately occurring event that is the

\footnotetext{
${ }^{24}$ Ibid., 16-17.
}

${ }^{25}$ Meghan E. Griffith, "Does Free Will Remain a Mystery? A Response to Van Inwagen," Philosophical Studies 124, no. 3 (2005): 264. 
agent-causing of the action...the agent's exertion of causal power (her agent-causing, if that is what we want to call it) is one and the same event as the action (one action with two descriptions)." ${ }^{26}$ While both of these may show that agent-causation can, to the contrary of van Inwagen, avert the Mind objection, I hope to do so with a response that remains largely neutral to the exact mechanism through which agents are able to or refrain from performing a certain action, thus making no assumptions about the mode of free will, be it agent causation, eventcausal variations, or some other theory.

\section{A New Response to the Mind Objection}

At the heart of van Inwagen's formulation of the Mind objection lies the component of chance and a seemingly randomly ordered sequence of different outcomes. It certainly seems that if decisions are a mere matter of chance, then the free-will thesis is false, as agents are not afforded the metaphysical ability to do otherwise than they do. However, I will show that in van Inwagen's example we can avoid any semblance of chance altogether by examining the nature of counterfactuals of freedom. To this end, I hope to show that (i) it is possible to produce a consistent outcome to which the ratio of a decision is 1 to 0 , and that (ii) this does not encroach upon free will. I conclude that the luck objection can therefore be averted, and that the incompatibility of free will and indeterminism is facile when based on this objection.

Van Inwagen's objection depends on the crucial premise that all replays will eventually converge to some non-1 or 0 ratio, thus giving the impression of chance in Alice's decisions. But what grounds have we to think this? By his own admission, van Inwagen thinks "we can't say what would have happened," only what probably would have happened. ${ }^{27}$ But where does this

\footnotetext{
${ }^{26}$ Ibid., 265.

${ }^{27}$ Peter van Inwagen, “Free Will Remains a Mystery,” Philosophical Perspectives 14 (2000): 14.
} 
probability come from? We can reasonably accept it comes from the assumption of indeterminism, since determinism would entail only a single possible outcome. But is this logically valid? Let $p$ be the determinist thesis ${ }^{28}$ and $q$ be the proposition that for any situation there can be only a single possible outcome.

\section{(1) $p \supset q$}

This follows from the definition of determinism itself. Let's turn to consider indeterminism, or the denial of determinism.

\section{(2) $\neg p$}

Now we must be careful not to reason like so:

$$
\text { (3) } \therefore \neg q
$$

Or alternatively

$$
\neg p \supset \neg q
$$

This would read that if determinism is false, then there cannot be only a single possible outcome. This material implication is obviously guilty of the formal fallacy of denying the antecedent, and so it cannot be accepted as a valid argument. Now, luck objectors usually make no strong claim that there necessarily cannot be only a single possible outcome, but the point is that the denial of determinism in no way logically rules out the proposition that for any situation there will be only a single outcome. This perhaps is the key to understanding where van Inwagen's objection fails. It could very well be that in situations where agents exercise free will, there will only be one outcome the agent ever enacts, no matter how many times they are in the situation. How could this be so? As an aside, it is important to note that there is an important difference between the fact that there can be only a single possible outcome in any given situation, and that there will be

\footnotetext{
${ }^{28}$ See definition of "Determinism”, p. 3.
} 
only a single outcome in any given situation. The former implies the latter, but these propositions are not logically equivalent. I shall return to this point later, but for now, let the reader note this distinction.

Returning to the Mind objection, let us examine van Inwagen's proposal that the ratio of outcomes will converge to approximately .5. As we have seen, there is no reason that this ratio must necessarily obtain. However, if the ratio could simply be 1 or 0 , we would lose any reason to think that the outcomes of Alice's decision are matters of chance. There is no logical contradiction between the free-will thesis and the claim that for any situation, there will only be one outcome. Not that there must be only one outcome, and not that there couldn't be other outcomes, but that there will be only one outcome. Still the question remains: how is it possible to achieve this ratio? Van Inwagen himself hints at a solution when he references the possible knowledge of other people or God as reason to think the outcome is not a matter of chance. ${ }^{29}$

\section{Approaching Whole Ratios}

A crucial underpinning of van Inwagen's argument appears to be the assumption that if the agent, in this case Alice, has free will and the freedom to choose between $A$ or not- $A$, and if she is put in the same situation repeatedly, she will eventually choose both. The ratio of outcomes (lying or telling the truth) will then begin to converge to some non-whole ratio. In note 16 of his paper, van Inwagen says he at least thinks it highly unlikely that the ratios will not converge, because "as the number of replays increases, the probability of 'no convergence' tends to $0 .{ }^{\prime 30}$ However, van Inwagen does not reveal how he arrives at this probability. As with all instances of probability, we must ask of van Inwagen, improbable relative to what? What

\footnotetext{
${ }^{29}$ Peter van Inwagen, "Free Will Remains a Mystery,” Philosophical Perspectives 14 (2000): 14.

${ }^{30}$ Ibid., 19.
} 
background information makes the non-convergence of the ratio of Alice's decisions improbable? Van Inwagen makes no strong claim about exactly what this background information could be. On determinism, there must necessarily be only ever one outcome for any given situation, so non-convergence is virtually certain there. So van Inwagen has to give good reason to think that the probability of Alice only ever making the same decision is low. Perhaps van Inwagen means "improbable relative to the truth of the free-will thesis." But even if the freewill thesis is true, one can think of a plethora of examples where the ratio may plausibly never converge.

\section{Easy Decisions}

To give a simple, relevant example, suppose recent DNC presidential candidate Bernie Sanders is in the position of choosing to endorse a remaining candidate after his loss to Hillary Clinton. He can choose between the DNC candidate Hillary Clinton, or the GOP candidate Donald Trump. ${ }^{31}$ Bernie Sanders is a staunch liberal and idealizes socialist values; Donald Trump therefore is anathema to him. After quick consideration, Sanders endorses Clinton for the 2016 presidential race. Now suppose, like in the case of Alice, God rewinds time to the minute before Sanders' choice to endorse a presidential candidate. Sanders again chooses to endorse Clinton. All well and good. Now God replays the situation 98 more times, totaling one hundred replays. Have we any reason to think Sanders will in any of these replays endorse Trump? Given the free-will thesis, it is perfectly possible for Sanders to choose Trump for any of these replays, so it certainly is not outside the realm of logical possibility. Even still, the mere possibility of the choice does not give us good reason to think that Sanders will indeed make that choice, no matter how many times he is in that situation. Of course, we could assign an arbitrary probability to his

\footnotetext{
${ }^{31}$ Of course, there may be other options - like abstaining from an endorsement or endorsing a third partybut for the sake of simplicity, as in the case of Alice, consider only these two possibilities.
} 
choice, say 999,999 to 1 . So after a million replays, Sanders may very well—just once—endorse Donald Trump. But even then, this would be to assume chance is the final arbiter of the decision anyway and fail to address the issue in full. In this case, it seems plausible, if not highly likely, that Sanders would never endorse Trump in any replay God might cause in reverting the universe to a certain position in time. Consider another example: you are given the choice between chocolate cake and strawberry shortcake for dessert at a dinner party hosted by your friend Ashley. Unfortunately, you are deathly allergic to strawberries, and no matter how much you love them, you know ingesting one means a trip to the hospital while risking death. You therefore choose the chocolate cake. The same situation as before occurs: unbeknownst to you, God rewinds time over and over to the minute before you make your confectionary choice. Will you ever make the choice of strawberry shortcake? I can think of no reason you ought, and the number of times you are in the situation seems to do nothing to steer your choice to the strawberry shortcake.

So the simple assumption of the free-will thesis plausibly does not provide the kind of background information necessary to make the non-convergence of outcome ratios improbable. In the case of choosing between highly preferable choices and noxious ones, it seems intuitively plausible that one will never choose the aversive option regardless of how many times they must make that choice. Van Inwagen's formulation of the luck objection may have no prowess in defeating the free-will thesis in cases such as these. This would mean, even if certain other situations are matters of chance, there are at least some actions which may be considered free that do not fall prey to chance. However, even if we do have free will in "easy" situations such as these, proponents of the free-will thesis would really want to have free will in the difficult situations as well, if not even more than the easy ones. That said, I'm certain Senator Sanders 
considers his ability to refrain from endorsing Donald Trump a very important freedom, even if it is an easy choice. But for more difficult situations like that of Alice, we may yet also find a nonconvergence outcome among God's replays.

\section{Difficult Decisions}

The problem (potentially) with examples like Bernie Sanders and dessert is that the decision is an easy one to make. In dealing with situations containing the possibility of more than one outcome, van Inwagen may object that Alice's case is problematic because of the apparent difficulty with which she makes the decision. Now, this does not seem to change the nature of decision making events. If decisions are a matter of chance, this fact is primary to the decision making itself. Van Inwagen's objection is based on the appearances of a thought experiment; however, these appearances do not ground (in the ontological sense) the problem of chance for free will, but rather would come about as a result of the truth of chanciness, and we are to infer from the examples that chance is an issue inductively rather than deductively. That is to say, if chance is the issue for free will, then it is the issue in all situations with the appearance of decision making, not just difficult cases. In theory, van Inwagen's version of the Mind argument should also apply to any decision God may roll back time on, even easy ones. So in order to avert the rebuttal of chance in the case of "easy decisions", van Inwagen would have to either claim that these decisions are actually not instances of freely willed decisions at all, or somehow otherwise show that easy decisions are still necessarily subject to chance without begging the question. I wouldn't begin to presume I know how he would respond to this, but I have no ideas myself as to how to go about this exercise. In any case, Alice's predicament is not so straightforward as Senator Sanders'. 
It is easy to show how, quite plausibly, there may be situations in which the nonconvergence of the ratio of outcomes is highly likely, but this is not so easy with cases like Alice. The non-convergence of the ratio is key to avoiding chance, and it seems very intuitive that the more difficult the situation is, the more balanced a ratio might obtain. After all, if we are able to choose between $A$ and not- $A$ like the free-will thesis suggests, and we could just as easily choose $A$ or not- $A$ in any given situation, it seems likely that if we had multiple "takes" for a situation and we were torn between $A$ and not- $A$, our outcomes would be varied. As van Inwagen says, "nothing we could possibly learn, nothing God knows, it would seem, should lead us to distrust

our initial inclination to say that the outcome of the next replay will be a matter of chance." 32 But could we learn something that would dissuade us from thinking there will be a convergence of ratios at all? Is there some kind of knowledge that would give us reason to think there could plausibly be non-convergence in difficult situations like Alice?

\section{Subjunctive Counterfactuals}

I think a very specific knowledge of certain true propositions could provide a way to avoid ratio convergence in difficult situations. If there is a true proposition taking a certain form about Alice's decision that an impeccable knower of some sort may know, I propose we would lose any semblance of chance in her decision making. This would hold no matter how many times Alice were put in a situation. How could this be so? Consider the following:

(1) "If Alice were in circumstance $C$, then she would perform the act $A . "$

This is a classic counterfactual conditional. We have an if clause in the subjunctive mood, and a then clause in the conditional mood, thus supplying us the nomenclature subjunctive counterfactual. How could counterfactuals help us in dealing with the Mind objection? To

\footnotetext{
${ }^{32}$ Ibid., 17.
} 
unpack this part of the solution, we must examine the nature of counterfactuals themselves, and see what they could possibly supply by way of an argument. The short story is this: if a being had perfect knowledge of a prior counterfactual proposition about Alice's decision, then that being's knowledge would dissuade us from ever thinking that there will be convergence like the kind proposed by van Inwagen. We would then be justified in thinking that no matter how many times God "rewound the clock," Alice would always freely make the same decision to either lie or tell the truth. Thus, any semblance of chance is lost, and free will seems compatible with indeterminism.

Counterfactuals give us if-then statements in the subjunctive mood. The subjunctive mood is what supplies the 'would' for the then clause at the end of counterfactual conditionals. This would allow us potential knowledge of what agents would do in any given situation in which they might find themselves. If these counterfactuals are true, then it appears that whoever or whatever knows them has very good reason to know what creatures would do in situations that are held constant. However, this admittedly smacks of determinism, especially since the antecedent of the counterfactual includes circumstances that are related to the subject's action. One way to go about resolving this difficulty would be to account for freedom in the counterfactual itself. Thus, we can modify (1) to avoid this difficulty:

(1a) "If Alice were in circumstance $C$, then she would freely perform the act $A . "$ Lest anyone think this modification begs the question in favor of the truth of the free-will thesis, remember that the Mind objection assumes the truth of indeterminism in its formulation, and that van Inwagen's primary concern is that freedom cannot be distinguished from chance even if freedom is indeed the mechanism through which Alice varies her decisions. I will explore the possibility of circularity further in Section $\mathrm{V}$, but let it suffice for now that I deny presupposing 
anything more than is presupposed by van Inwagen's argument itself. In order to show that these kinds of counterfactuals cannot be used, one would have to provide reason to think there is some kind of logical incoherency in their construction. In Section V, I will return to the most prominent objection against counterfactuals of this kind: that truly knowing these counterfactuals involves a kind of foreknowledge that is freedom-prohibiting. I hope to show there that this folk understanding of foreknowledge relies on a mistake in modal logic that precludes the possibility of freedom in foreknown actions.

Interestingly, philosophers of religion have used these kinds of counterfactuals of creaturely freedom to probe how God might interact with the world, particularly in regards to foreknowing freely willed acts. In this sense, counterfactuals of creaturely freedom are defined as "counterfactuals of the form If $\mathrm{S}$ were in $\mathrm{C}, \mathrm{S}$ would freely do A, where $S$ is a created agent, $A$ is some action, and $C$ is a set of fully specified circumstances including the whole history of the world up until the time of $S^{\prime}$ s free action. ${ }^{\prime 33}$ God himself would be the most obvious candidate for knowing such a proposition. In theology, this position is called Molinism after the $16^{\text {th }}$ century Spanish Jesuit theologian Luis de Molina, and is an account of divine providence that is compatible with human freedom. However, there could possibly be other candidates for having such knowledge, like a time-traveler, or perhaps Alice herself, though she could not justify this belief. In any case, the counterfactual must be true; who knows it is not of particular import. As an important aside, the name counterfactual is somewhat of a misnomer for the most important of these propositions. These are called counterfactuals because they often are abstracted from the actual world, but it is the case that one of these true counterfactuals will be the case in the actual world. Thus, it seems odd to refer to it as a counterfactual, since it is not

\footnotetext{
${ }^{33}$ William L. Craig, "Middle Knowledge, Truth-Makers, and the Grounding Objection," Faith and Philosophy 18 (2001): 337-52.
} 
counter to the fact. This particular proposition will be the crux of my solution to van Inwagen's problem. "Counterfactual of freedom" is somewhat of an idiosyncratic term in this case, and perhaps it would be more accurate to refer to this proposition as a true subjunctive conditional. However, let not the reader interpret counterfactual strictly in this case.

The key to this solution's success will be whether these counterfactuals are actually true. Do these counterfactuals indeed have a discrete truth value, and if so, are they true? Note that the question is not necessarily ontological. These kinds of counterfactuals do not need to exist as objects (be they propositions or what have you), but simply need to be true. Do we have any reason to think that they correspond with reality? Philosopher of religion William Lane Craig thinks that we do, and I will consider two of his reasons here. First, we have good reason to believe them on the basis of our own experience with the knowledge of these counterfactuals. ${ }^{34}$ We ourselves seem to know what we would do in certain situations. Not all, of course, but not infrequently in our experience, we can attest to the truth of statements like: "If it were raining outside, I would fetch my umbrella." We make decisions based on the truth or falsity of these counterfactuals. We might make certain preparations for scenarios like emergencies based on the truth of these kinds of counterfactuals. Second, these counterfactuals seem subject to the Law of Conditional Excluded Middle, and therefore must have a truth value one way or another. ${ }^{35}$ So for any counterfactual of creaturely freedom—-plausibly — the consequent must be either true or false. As Craig puts it, "since the circumstances $C$ in which the free agent is placed are fully specified in the counterfactual's antecedent, it seems that if the agent were placed in $C$ and left free with respect to action $A$, then he must either do $A$ or not do $A$. For what other alternative is

\footnotetext{
${ }^{34}$ Ibid.

${ }^{35}$ Ibid.
} 
there?"36 It seems to me that one must either reject the Law of Conditional Excluded Middle entirely or in some qualified form with strong justification to avoid the conclusion from the second reason. Alvin Plantinga offers another argument for the existence of at least some true counterfactuals of creaturely freedom. ${ }^{37}$ Plantinga supposes that a man is given a bribe of $\$ 20,000$ and accepts it. Plantinga further supposes that if on that same occasion the man was given $\$ 35,000$ instead for the same service, he would surely accept that bribe too. Therefore, it seems that there is at least one true counterfactual of freedom. Interestingly, van Inwagen himself delivered a lecture on his beliefs about counterfactuals of creaturely freedom. He believes that all counterfactuals of freedom are false for the same reason he believes his version of the Mind objection holds up against agent causation. ${ }^{38}$ Should God revert time back to the instant before an agent commits a free act $A$, given incompatibilism, the man "might" 39 choose either $A$ or notA. If this is possible, then, per van Inwagen, it becomes impossible to distinguish which possible worlds are closer to the actual world (that is, more probable), ${ }^{40}$ and therefore the counterfactuals in the actual world are false, because we cannot definitively say which course of action (either $A$ or not-A) would have occurred. ${ }^{41}$ Craig thinks that van Inwagen's response actually goes to support the Molinist position. For Craig, each replay is an entirely new circumstance on its own, and therefore would have a unique counterfactual that is either true or false due to the Law of

${ }^{36}$ Ibid.

${ }^{37}$ Alvin Plantinga, The Nature of Necessity (Oxford: Clarendon Press, 1973), 177.

${ }^{38}$ Peter van Inwagen, “Against Middle Knowledge,” Midwest Studies in Philosophy 21 (1997): 225-236.

${ }^{39}$ I use scare quotes because I think van Inwagen is mistaken in using "might" for reasons we will see in the next section.

${ }^{40}$ Van Inwagen uses David Lewis’ semantics to describe counterfactuals.

${ }^{41}$ Ibid., 230. Van Inwagen freely admits that, should one find Lewis' semantics for counterfactuals in some way flawed, then his argument is conditional and would fail. 
Conditional Excluded Middle. ${ }^{42}$ This may strike us as odd initially, as the only distinction between replays is God's decision to replay, his knowledge of which replay he is currently enacting, and the bare fact of its being another replay. The facts of the physical world are presumably the exact same, and given indeterminism, the agent "might" therefore (according to van Inwagen) choose differently. Whether Craig's objection is forceful or not, I do not have argument for it. At least on the surface level, I see no reason that there couldn't be new counterfactuals for each replay, but I will not make an argument for it here. Significant distinctions in counterfactual semantics

I believe now would be a good time to return to several points I made earlier in order to stay consistent with van Inwagen's advice to very clearly define potentially confusing terms. In particular, usage of the words might, could/can, and would/will can become incredibly vague in dealing with the problem of free will and counterfactual semantics. I will take these in turn, explain my usage, and hopefully show that van Inwagen's objections to the truth of any counterfactuals of freedom can be avoided.

Might. Perhaps the most confusing of all the terms, might is possibly at the root of many of the misunderstandings surrounding counterfactual semantics. In everyday language, we use might to indicate a possible outcome from a certain set of specified or unspecified circumstances. However, any time the word might is used, there is a fundamental assumption built into the term that distinguishes it from the others I will consider. In the usage of might, the user precludes any kind of certainty about the outcome to which they are referring. It is always (or as I will argue, should always be) used from the perspective of the past looking forward at the uncertain future.

\footnotetext{
42 William L. Craig, "Middle Knowledge, Truth-Makers, and the Grounding Objection," Faith and
} Philosophy 18 (2001): 352. 
Sometimes in referring to the past, we will say things like "I might have done differently than I in fact did." However, sometimes what we actually mean is merely "I could have done differently than I in fact did." In the previous case, might means "I could have done differently than I in fact did, and I am uncertain as to whether or not I actually would have." Might implies a kind of uncertainty that will fundamentally block any kind of counterfactuals of freedom. Regarding counterfactuals of freedom, we care about what an agent would have done; regarding free will itself, we care about what an agent could have done; what that agent might have done is up to her and her own personal preferences. This points to another confusing way might can be used. The category of indeterministic events is broad, and different usages of might in its subcategories carry different implications. For example, with indeterministic events of the sort that we encounter in quantum indeterminacy, the differences between might and could are virtually insignificant. Take for example

"This isotope might decay at time $t . "$

and

"This isotope could decay at time $t . "$

There is no significant difference between these two, particularly because the isotope has no say in its decay. They both seem to be true. However, in terms of indeterministic free choices (remember: choices simply not determined by the conjunction of the past and the laws of nature), might and could have very important differences, especially if we consider counterfactuals. Take for example

"I might drive my car off the bridge at time $t . "$

and

"I could drive my car off the bridge at time $t . "$ 
If driving the car off the bridge is a choice entirely up to me (that is, no particular mechanical failure of the car causes me to careen off a bridge), then while it is obvious the latter is plausibly be true, it is not so of the former. I would never consider driving my car off the bridge an option, even if I am free (that is, able) to do so. The way van Inwagen uses might to argue against true counterfactuals of freedom prevents the possibility of true counterfactuals of freedom in the first place. Thus, we ought not use might when considering the truth of counterfactuals of freedom lest we beg the question in favor of their falsehood. In fact, van Inwagen himself even acknowledges (to the chagrin of Daniel Dennett) that might is ambiguous in an essay written after his argument against true counterfactuals of freedom. ${ }^{43}$ Some may argue that we must use might in order to preserve indeterminism and freedom, but I will argue against this in Section V where I deal with the folk objection that foreknowledge is freedom-prohibiting.

Could/can and would/will. To recap from earlier, usage of could simply indicates the possibility of an outcome without making any sort of judgement whatsoever about its certainty or uncertainty. Regarding free actions and therefore counterfactuals of freedom, might and could are not interchangeable. Could is obviously directly related with can, and in this context is primarily concerned with the case of counterfactuals. Would is a term of certainty about a considered act, and being the past form of will, is used for counterfactuals. Here I will also return to a distinction I promised to discuss earlier. ${ }^{44}$ I referred to the phrases "can only ever" and "will only ever." The main distinction I would like to make here is that while the first is freedomprohibiting, the second is not. "Can only ever" implies that an agent would have no control over whatever outcome the phrase modifies. It directly contradicts the free-will thesis in that the agent

\footnotetext{
${ }^{43}$ Peter van Inwagen, "How to Think about the Problem of Free Will," The Journal of Ethics 12, no. 3-4 (2006): 332 .

${ }^{44}$ See p. 14.
} 
does not have the ability to refrain from doing that act. "Will only ever" does not carry that same implication. We can return to the case of Senator Sanders here to see this distinction. As we have established, it is entirely plausible that, put in the exact same situation ad infinitum, Senator Sanders will never choose to endorse Donald Trump. It is plain that this truth does not encroach upon his freedom; nothing about its being true directly implies Senator Sanders does not have both the ability to endorse and refrain from endorsing Trump. This distinction will solidify the protected truth of the free-will thesis in using counterfactuals of freedom as a defense against van Inwagen's version of the Mind objection.

The Counterfactual Solution

Relating all this back to van Inwagen's thought experiment, we can examine (1a) in more detail. Alice's circumstance now includes the entire history of the world up until the point at which she makes the decision. This will hold constant the outcome of each scenario in which God replays time where she will make her decision to either lie or tell the truth. Thus, no matter how many times Alice is subject to a rollback of time to again put her in $C$, if (1a) is true, she will only ever do A. Consequentially, the problem posed by van Inwagen is dissolved, for the ratio of outcomes will never approach anything other than 1 or 0 , and we would have no reason to think that the outcomes are a mere matter of chance. The truth of the counterfactual of Alice's free decision therefore averts the force of van Inwagen's objection by providing reason to believe one of the key assumptions is flawed.

The first facet of this response we must protect is that of the freedom in Alice's decision. If she only will ever do $A$, is it really true that she could refrain from doing $A$ ? I briefly alluded to this in the previous section on the will/can distinction, but there is another way of looking at the freedom permitting aspects of this response. We may ask, if Alice will only ever do $A$, are there 
any possible worlds in which she will not do $A$ ? And if not, then was $A$ really a free act?

Considering possible worlds, there would still be possible worlds where Alice chooses to refrain from $A$ because (1a) is only contingently true. ${ }^{45}$ For further discussion of possible worlds and counterfactuals of creaturely freedom, see and Robert J. Hartman's ${ }^{46}$ and William Lane Craig's ${ }^{47}$ writings on the subject. If the truth of these counterfactuals do not limit the possibility of any agent's ability to choose to perform or refrain from performing an act, I contend that the Molinist-style response to van Inwagen is efficacious in solving the problem of chanciness.

\section{Objections}

There are several grounds on which to challenge the Molinist-style replies to van Inwagen's version of the Mind argument. The primary challenges I will consider are of four kinds: 1) Challenges based on apparent circularity in counterfactuals of freedom; 2) challenges based on the intuition that foreknown facts of creaturely freedom are incoherent (that is, freedom prohibiting); 3) challenges based on reformulating the Mind argument to account for true counterfactuals of creaturely freedom; and 4) challenges based on the grounding of the truth of counterfactuals of freedom.

\section{Circularity}

Someone might object that in formulating the counterfactual as one of freedom, I have begged the question in favor of free will and therefore I should be ashamed of myself. However, I have not begged the question because I have assumed nothing that van Inwagen's problem doesn't take for granted itself. I have also not taken as true the conclusion of my argument and

\footnotetext{
${ }^{45}$ Robert J. Hartman, "Counterfactuals of Freedom and the Luck Objection to Libertarianism," (Forthcoming in Journal of Philosophical Research), 7.

${ }^{46}$ Ibid.

${ }^{47}$ William L. Craig, "The Difference Between Possible and Feasible Worlds,” Reasonable Faith, May 20, 2007, http://www.reasonablefaith.org/the-difference-between-possible-and-feasible-worlds.
} 
used that truth to give support for the premises of that very conclusion. Let me be clear, I am not arguing for the existence of free will (or the truth of the free-will thesis), at least not directly. My goal is simply to show that van Inwagen's version of the Mind objection will not perform as he thinks it shall, given the very assumptions of his own argument itself. Recall, van Inwagen's argument assumes both the truth of incompatibilism and indeterminism. Should I have taken for granted the existence of true counterfactuals of freedom to argue against determinism, I indeed may have been guilty of circularity, but this is not the case. Van Inwagen's case rests on the indistinguishability of chance from legitimate freedom; it asks what we might expect from a situation given a few key assumptions, and then on the basis of what we might observe, concludes that indeterminism and free will are incompatible. In fact, van Inwagen even assumes agent causation to be true in the argument: "I will assume - for the sake of argument - that agent causation is possible, and that it in fact exists." 48 I have done nothing more than this in positing that there are counterfactuals of freedom. My concern is to show that, given van Inwagen's very assumptions, we ought not expect to see what he thinks we ought to expect to see. Thus, this objection will not show that the counterfactual solution is untenable as a response to the Mind argument.

\section{Foreknowledge and Freedom}

Foreknowledge has always been problematic with regards to free acts. The folk intuition is that a foreknown future is irreconcilable with any potential free acts. This objection concerns itself primarily with the coherency of counterfactuals of freedom. If a foreknown future is incompatible with free acts, then a similar argument can be made that counterfactuals of freedom are incoherent and therefore cannot exist. The most obvious offender in this case is God. If God

\footnotetext{
${ }^{48}$ Peter van Inwagen, “Free Will Remains a Mystery,” Philosophical Perspectives 14 (2000): 1.
} 
in his omniscience knows future events with perfection, how is it possible for agents to make a genuine free decision between two options? I believe the simplest answer lies in that God's foreknowing such a fact is contingent. Contingent on what? Contingent on the agent making the decision. The agent's decision itself is what makes the counterfactuals correspond with reality, and therefore God knows this fact because it is true. The belief itself may possibly occur temporally prior in God's mind, but the decision itself is logically prior to its being known by God. This is all to say that if the agent were to choose something different, God would foreknow that action instead. Thus, there is no freedom-permitting necessity of these counterfactuals. So it would be without God as well. These counterfactuals are contingently true because of the agent's action, whether anyone genuinely knows them or not. There is another response to this folk intuition by purporting to show a flaw in the modal logic of the objector.

Stephanie Rennick discusses this folk intuition extensively and offers a multitude of reasons that it might be mistaken, the most prominent of which being a mistake made in modal logic. ${ }^{49}$ She claims that "[ [] he obvious response is that claiming weak predestination entails metaphysical fatalism involves a modal fallacy: moving from the truth of $p$ to its necessity. That is, from necessarily (if $p$ is true then $p$ ) - the necessity of the conditional - to necessarily $p$, the necessity of the consequent.. ${ }^{.50}$ That is to say, if God knows a true counterfactual of Alice's free act, then necessarily Alice will perform that act. But that does not make Alice's act itself necessary and therefore fated in a sense that is incompatible with freedom. I am convinced that this argument is persuasive, so I will not attempt to modify it here. Rennick's dissertation contains wonderfully detailed, carefully considered arguments that this folk intuition indeed

\footnotetext{
${ }^{49}$ Stephanie Rennick, "Foreknowledge, Fate and Freedom," (PhD diss., University of Glasgow, 2015), 26. ${ }^{50}$ Ibid.
} 
commits the modal fallacy described above. Her work is another great resource for looking deeply into this protest from the opposition.

\section{Reformulating van Inwagen's Argument}

Another objection to this solution involves reformulating van Inwagen's argument in such a way that the truth of counterfactuals of freedom does not affect the argument's conclusion. Dan Sheffler attempts to do just this in response to a conference paper delivered by Hartman. ${ }^{51}$ Sheffler modifies the argument to take the following form: Since counterfactuals like (1a) are only contingently true, then there must be a set of at least one possible world with a shared exact history where Alice chooses not $A$. The histories will diverge after that decision. Suppose God picks at random from the entire set of possible worlds with a shared exact history. If we observe a convergence of ratios similar to that of van Inwagen's original thought experiment, we would again have no reason to think the decision on Alice's part is anything more than a mere matter of chance. Hartman gives a similar argument. ${ }^{52}$ He supposes that there is a large set of type-identical worlds with remote, causally effete differences. Thus, circumstance $C^{\prime}$ of (1a) of these worlds differ by token, but not by type. An example would be a possible world identical to the actual world except for a speck of dust in a different place immediately after Planck time. Therefore, it is possible that Alice chooses not- $A$ in different token-circumstances but same type-circumstances. We may then observe Alice in these different circumstances ( $C, C^{\prime}, C^{\prime \prime}$, and so on), and if we observe Alice doing not- $A$, we may be left with the same intuition we had in van Inwagen's version. To summarize, Hartman changes the states

${ }^{51}$ Dan Sheffler, "Why Molinism Does Not Help with the Rollback Argument," (presentation, Society of Christian Philosophers, Trinity College, March 2014).

${ }^{52}$ Robert J. Hartman, "Counterfactuals of Freedom and the Luck Objection to Libertarianism," (Forthcoming in Journal of Philosophical Research), 7. 
of the world before Alice's decision and Sheffler changes them after Alice's decision. Selecting from these new sets of possible worlds in which counterfactuals of freedom are taken for granted will provide a similar intuition as in van Inwagen's original problem, reinstating the supposed incompatibility of free will and indeterminism.

There are a few ways to go about responding to these objections. Hartman's objection does not carry as much force as Sheffler's, as the circumstances in the antecedent clause of the counterfactual are not identical. It may be argued that we simply are not in a good enough position to know what we really would observe and it is ambiguous as to whether we would indeed be left with the same intuition as van Inwagen's. However, it seems to me the most obvious line of defense is that, if the counterfactuals' conditional circumstance includes the entire history of the world, then there are simply different counterfactuals about Alice's free decision. Freedom only ever is in jeopardy on a case by case basis. The freedom of agents has no obvious trans-world properties, and so for this objection the differences in outcomes between same type- but different token-circumstances are at best unusual and at worst irrelevant.

Sheffler's argument cannot be so avoided. His version assumes the exact same circumstances in the conditional clause. At first, as Sheffler even suggests, we may insist that all worlds in which $C$ obtains are also worlds in which Alice does $A$. However, Sheffler thinks this violates incompatibilist sensibilities as nothing about the laws of nature and the past determine an agent's action. So identical circumstances will not necessarily produce identical results. Molinists have typically dealt with this problem by distinguishing between possible worlds and feasible worlds. Identical circumstance worlds where Alice does not- $A$ are possible, but they are not feasible. Sheffler describes these worlds as "all logically, nomologically, and metaphysically 
possible," but infeasible because they could never be actual. ${ }^{53}$ This is because counterfactuals like (1a) are all true prior to the existence of any world. From God's perspective, since he would have knowledge of all of these true counterfactuals, he could not actualize any of these possible worlds. Sheffler admits this could possibly be the case, but that this solution presents an even further problem involving any counterfactuals of freedom. This is due to the contingency of the counterfactuals themselves. This in turn may still make the decision seem chancy regardless. Sheffler explains:

Nothing about logic, mathematics, the laws of nature, the history or initial position of the universe, the past deeds of Alice, or even her character can possibly determine the truth value of [counterfactuals of freedom]. No event in Alice's brain prior to her choice or even anything about the knowledge of God makes it the case that Alice will tell the truth in these circumstances. Nevertheless, Molinism insists, it is a fact about the actual world (and any world God could have created) that Alice would tell the truth in these circumstances. ${ }^{54}$

This is a challenge to the Molinist to point to something that grounds the truth of (1a).

The Grounding Objection

A final objection levied at philosophical positions involving counterfactuals of freedom arises on the basis that there is no grounding for the truth of such counterfactuals. Sheffler thinks that any attempt to provide such grounding will collapse the Molinist account into compatibilism. Now that it is clear that reformulations of van Inwagen's argument rely on the grounding objection to be persuasive, the main focus becomes whether the grounding objection is forceful. The primary claim of the grounding objection is that there is nothing to make these counterfactuals of freedom true, so therefore they are either uniformly false or have no truth

\footnotetext{
${ }^{53}$ Dan Sheffler, "Why Molinism Does Not Help with the Rollback Argument," (presentation, Society of Christian Philosophers, Trinity College, March 2014).

${ }^{54}$ Ibid.
} 
value at all. This poses an obvious problem for the Molinist, and likewise for the counterfactual solution to van Inwagen's Mind objection; for if counterfactuals of this sort are false, then van Inwagen's chancy intuitions remain intact. What can be said in reply to this objection? First, it is important to understand what exactly it presumes. It seems that the grounding objection relies on a correspondence theory of truth, particularly a truth-maker theory or verificationist theory. Commonly put, truth-makers are posited as entities defined as that in virtue of which a sentence and/or proposition is true. Related to this discussion is the disquotation principle, which is the principle that " $p$ " is true iff $p$ where $p$ represents a true proposition expressed by the sentence "p". This principle is used to disclose propositions in sentential form. As an aside, Craig warns us not to try and provide a causal connection between the truth-bearer and the truth-maker. Most truth-maker theorists are quick to point out that the relationship between truth-bearers and truthmakers is not causal. Craig uses the example "Baal does not exist" to illustrate this point. ${ }^{55}$ Baal's non-existence, sufficient for the truth that Baal does not exist, obviously cannot be a cause of anything.

So the grounding objector may not demand a causal relationship for the grounding of the truth of counterfactuals, but it does seem that the grounding objector presupposes that "in order to be true, counterfactuals of freedom must have truth-makers that either are or imply the existence of concrete objects." ${ }^{, 56}$ For if not, then perhaps the truth-makers for these counterfactuals could be the states of affairs that correspond to the world, or they may simply not have any truth-makers at all. Many truth-maker theorists do not hold that every single true statement requires a truth-maker, a position Barry Smith calls truth-maker maximalism. There

\footnotetext{
${ }^{55}$ William L. Craig, "Middle Knowledge, Truth-Makers, and the Grounding Objection," Faith and Philosophy 18 (2001): 337-52.

56 Ibid.
} 
has been no argument from the grounding objector that counterfactuals of freedom could not possibly fall into that category of true statements not requiring a truth-maker. Timothy O'Conner proposes that future-tensed propositions have no truth-makers but rather truth-conditions, that they are true just in case their relevant present-tensed formulations will have grounds for their truth. And, just as future-tensed propositions may not have truth-makers but nevertheless have truth-conditions, so too could be the case for counterfactuals of freedom. ${ }^{57}$

However, suppose counterfactuals of freedom do require truth-makers. Craig thinks the most obvious candidate for these truth-makers would be the states of affairs disclosed by the disquotation principle. ${ }^{58}$ Only if the grounding objector presupposes that only existing concrete objects are candidates for truth-makers will states of affairs be unable to serve as the counterfactuals' truth-makers. However, Craig shows that there are many true statements with no possible concrete truth-maker, like "Torturing the Iraqi prisoners in Abu Ghraib is wrong." ${ }^{59}$ The truth of that statement cannot be grounded in the situation of the persons involved; it would still be true whether or not there are any prisoners in Abu Ghraib at all. Therefore, unless the grounding objector can somehow show that, specifically, the states of affairs disclosed by the disquotation principle are impossible as candidates for truth-makers, then the grounding objection carries no force. Thus it appears the counterfactual solution will hold up to scrutiny and remain a plausible response to van Inwagen's Mind objection.

\footnotetext{
57 Timothy O’Connor, “The Impossibility of Middle Knowledge,” Philosophical Studies 66 (1992): 155156.

${ }^{58}$ William L. Craig, "Middle Knowledge, Truth-Makers, and the Grounding Objection," Faith and Philosophy 18 (2001): 337-52. (2006): 161-6.
} 


\section{Further Reading}

If the counterfactual solution is successful (and it appears so), then we have made significant progress in the problem of free will. Recall: the problem of free will involves finding which of the three kinds of arguments involving free will are fallacious. It seems we have an answer. Arguments of the sort that assert the incompatibility of free will with indeterminism are fallacious. As we have also seen, arguments that assert the incompatibility of free will with determinism are powerful. What of the third kind of argument? That is, what are the arguments for the necessity of free will itself? Van Inwagen mentions one such argument primarily based on the existence of negative moral value judgements:

Suppose that your friend Alice has told a lie, and that you say to her (stern moralist that you are), (a) You ought not to have lied. Making statement (a), it would seem, commits you to the truth of (b) You ought either to have told the truth or to have remained silent. And (b), in its turn, commits you to the truth of (c) You were able either to tell the truth or [inclusive] remain silent...Statement (c) commits you to the truth of (d) You were able to do something you did not do, and (d) commits you to the truth of...the free-will thesis. ${ }^{60}$

Thus, there can be no negative moral value judgements if the free-will thesis is false. However, it is apparent to all that people do not always do what they ought to do. Arguments of this sort are typically fleshed out in terms of moral responsibility as a whole, but it is not within the scope of this essay to address these kinds of argument in detail. Other arguments for the existence of free will involve treating free will as a properly basic belief. In other words, without overwhelming evidence for the truth of a defeater for this belief, it is justified apart from a deductive argument for it. The free-will thesis does seem to be one such belief. However, if the incompatibilist arguments are successful, then evidence for the truth of determinism will prove to be a defeater for the proper basicality of the free-will thesis. However, it is far from evident that determinism

\footnotetext{
${ }^{60}$ Peter van Inwagen, "How to Think about the Problem of Free Will," The Journal of Ethics 12, no. 3-4 (2006): 328.
} 
is true. Most arguments that entail determinism are arguments for metaphysical naturalism (the thesis that the only things that exist are physical and nothing supernatural exists). For a further discussion of naturalism, see Dennett's and Plantinga's arguments for and against. ${ }^{61}$ I shall therefore leave with the prima facie correct arguments for incompatibilism and the necessity of free will. Should these arguments hold under scrutiny, then the case for free will seems strong.

\section{An Account of Free Will}

Finally, it may be demanded that the libertarian should not only give a definition of the free-will thesis, but they should also give the mechanics through which free will plays out in the world. I have remained neutral to this to propose an all-encompassing response to van Inwagen — and also for the sake of the scope of this essay — but I shall here offer some possibilities. A prominent account of libertarianism is agent causation. Alice, the agent herself, brings about the events of her either telling the truth or telling a lie. Many times, the agent is thought of as some substance apart from the physical world. This position is often referred to as substance dualism, and is largely rejected on grounds of its incompatibility with naturalism. Many such arguments are actually from epistemological naturalism, which does not obviously entail metaphysical naturalism, which is the truly conflicting belief. If one were convinced naturalism was false, then substance dualism may be an open option. Plantinga offers such an argument for "substantial dualism." ${ }^{62}$ However, the most prominent libertarian philosopher, Robert Kane, does not rely on substance dualism to arrive at the free-will thesis.

Kane proposes a kind of free will called event-causal free will. He does so with the conjunction of what he calls ultimate responsibility (UR) with self-forming actions (SFAs). Kane

\footnotetext{
${ }^{61}$ Daniel Dennett and Alvin Plantinga, Science and Religion: Are They Compatible? (New York: Oxford University Press, 2011).

${ }^{62}$ Alvin Plantinga, “Against Materialism,” Faith and Philosophy 23, no. 1 (2006).
} 
says "the basic idea of Ultimate Responsibility is this: To be ultimately responsible for an action, an agent must be responsible for anything that is a sufficient cause or motive for the action's occurring. ${ }^{\prime 3}$ SFAs are "earlier acts by which we formed our present characters. ${ }^{.64}$ Kane’s solution is to at least trace UR back to an agent's SFAs, and thus provide an account of free will. In doing so, UR requires the free-will thesis to be true. The primary difference between agent causation and event-causal free will is that Kane's theory embraces indeterminism rather than shying away from it. In Alice's case, since the indeterminacy only occurs between options that are both willed by the agent, no matter what she does, she will have done what she freely willed to do. That is to say, on Kane's view, Alice both willed to lie and willed to tell the truth. She simply had trouble deciding which one of her desires (which spring from her will) to gratify. I think this solution resonates with experience on some level. We all at one point have suffered from a conflict of our own will. However, it does seem to leave the libertarian unsatisfied if they want an account of complete control over every individual action they could possibly commit.

These are two ways of a myriad to account for free will. If any of these accounts are plausible and coherent, then the libertarian has adequately responded to the demand to provide an account of how free will occurs in the world.

\section{Conclusion}

In sum, the problem of free will arises from three prima facie arguments about free will. All three cannot be true. The incompatibilist Consequence Argument is persuasive, but a new problem arises implicating the incompatibility of free will with indeterminism. However, this problem can be solved by the truth of counterfactuals of creaturely freedom. Thus, we lose any

\footnotetext{
${ }^{63}$ Robert Kane, "Libertarianism," in Four Views on Free Will, by John Martin Fischer, Robert Kane, Derk Pereboom, and Manuel Vargas (Oxford: Blackwell, 2007), 14.

${ }^{64}$ Ibid.
} 
chancy intuitions about free actions, and we no longer need to lose sleep over our actions being no more than a dice roll. This response does not to succumb to the main criticisms lodged against because these criticisms are founded on faulty intuitions and incomplete ontologies of truth.

If the luck objection fails, then libertarians are free to hold to the free-will thesis without any worries about incompatibility with indeterminism. They may pursue whatever accounts of free will they find most persuasive unhindered by the fear that their decision will be a matter of luck. 


\section{Bibliography}

Chisholm, Roderick M. "Freedom and Action.” In Freedom and Determinism, edited by Keith Lehrer, 11-44. New York: Random House, 1966.

Craig, William L. "Middle Knowledge, Truth-Makers, and the Grounding Objection." Faith and Philosophy 18 (2001): 337-52.

—. "Ducking Friendly Fire: Davison on the Grounding Objection." Philosophia Christi 8 (2006): 161-6.

. "The Difference Between Possible and Feasible Worlds." Reasonable Faith. May 20, 2007. http://www.reasonablefaith.org/the-difference-between-possible-and-feasibleworlds.

Dennett, Daniel, and Alvin Plantinga. Science and Religion: Are They Compatible? New York: Oxford University Press, 2011.

Fischer, John M. “Compatibilism.” In Four Views on Free Will, by John Martin Fischer, Robert Kane, Derk Pereboom, and Manuel Vargas, 56. Oxford: Blackwell, 2007.

Frankfurt, Harry G. "Alternate Possibilities and Moral Responsibility.” Journal of Philosophy 66 (1969): 828-39.

Griffith, Meghan E. "Does Free Will Remain a Mystery? A Response to Van Inwagen." Philosophical Studies 124, no. 3 (2005): 261-69.

Hartman, Robert J. "Counterfactuals of Freedom and the Luck Objection to Libertarianism." Forthcoming in Journal of Philosophical Research.

Kane, Robert. "Libertarianism.” In Four Views on Free Will, by John Martin Fischer, Robert Kane, Derk Pereboom, and Manuel Vargas, 5-43. Oxford: Blackwell, 2007a.

McKay, Thomas J., and David Johnson. "A Reconsideration of an Argument against Compatibilism.” Philosophical Topics 24 (1996): 113-22.

O’Connor, Timothy. “The Impossibility of Middle Knowledge.” Philosophical Studies 66 (1992): 155-156.

Pereboom, Derk. Living without Free Will. Cambridge: Cambridge University Press, 2001.

Plantinga, Alvin. The Nature of Necessity. Oxford: Clarendon Press, 1973.

—_. "Against Materialism." Faith and Philosophy 23, no. 1 (2006). 
Rennick, Stephanie. "Foreknowledge, Fate and Freedom." PhD diss., University of Glasgow, 2015.

Sheffler, Dan. "Why Molinism Does Not Help with the Rollback Argument." Presentation at the Society of Christian Philosophers, Trinity College, March 2014.

Strawson, Peter F. Freedom and Resentment, and Other Essays. Abingdon: Routledge, 1963.

van Inwagen, Peter. An Essay on Free Will. Oxford: Clarendon Press, 1983.

__. "Against Middle Knowledge." Midwest Studies in Philosophy 21 (1997): 225-236.

_ . "Free Will Remains a Mystery." Philosophical Perspectives 14 (2000): 1-19.

—. "How to Think about the Problem of Free Will." The Journal of Ethics 12, no. 3-4 (2006): 327-41. 